\title{
PERSISTENT ORGANOCHLORINE POLLUTANTS IN OBESE WOMEN AFTER DIET INDUCED WEIGHT LOSS: FIVE YEARS FOLLOW UP STUDY
}

\author{
Dana Müllerová',, , Dagmar Matějková2, Jana Dvořáková1, Luděk Müller ${ }^{3}$, Jan Rosmus ${ }^{4}$, Kateřina Kovářová2 \\ ${ }^{1}$ Department of Public Health, Faculty of Medicine in Pilsen, Charles University in Prague, Pilsen, Czech Republic \\ ${ }^{21 s t}$ Medical Department, Charles University Medical School and Faculty Hospital in Pilsen, Pilsen, Czech Republic \\ ${ }^{3}$ European Centre of Excellence, New Technologies for Information Society, Faculty of Applied Sciences, University of West Bohemia, Pilsen, \\ Czech Republic \\ ${ }^{4}$ Department of Chemistry, State Veterinary Institute, Prague, Czech Republic
}

\section{SUMMARY}

Aim: Persistent organochlorine pollutants (POPs) from the environment are still bioaccumulating in human tissues. The aim of our study was to analyze the development of plasma POPs levels in obese women in relationship with their weight loss success in five year follow-up study.

Methods: 20 obese women aged 25-73 years were studied just before and after having completed a 3 month controlled low calorie diet (LCD) intervention ( $5 \mathrm{MJ}$ daily), and again after 6 and 60 months since the beginning of the study. Body weight and plasma levels of 7 POPs were measured: polychlorinated biphenyls (PCB) 153, 138, 180; 2,2-bis(4-chlorophenyl)-1,1,1-trichloroethylene (p,p'-DDE); 2,2-bis(4-chlorophenyl)1,1,1-trichloroethane (p, $p^{\prime}$-DDT), hexachlorocyclobenzene (HCB), hexachlorocyclohexane $\beta(\mathrm{HCH} \beta)$.

Results: Data shows that after 3 months of a completely controlled restrictive diet regimen, the weight loss was associated with an increase in POP plasma levels. However, after a five year follow-up, there were no differences in POPs plasma levels between those who kept losing weight or maintained the initial weight (WL/M) and the group of weight gainers (WG), except for HCB where the WG had a significantly higher level $(p<0.05)$.

Conclusions: These results suggest that contrary to the long-term weight gain, the long-term weight loss or weight maintenance caused by diet restriction is associated with lower plasma levels of HCB.

Key words: persistent organic pollutants, hexachlorocyclobenzene, low calorie diet, body weight changes

Address for correspondence: D. Müllerová, Charles University, Faculty of Medicine in Pilsen, Department of Public Health and Preventive Medicine, Lidická 4, 30166 Pilsen, Czech Republic. E-mail: dana.mullerova@lfp.cuni.cz

\section{INTRODUCTION}

Persistent organochlorine pollutants (POPs), organochlorine pesticides and polychlorinated biphenyls (PCBs) are synthetic chemicals that have been released into the environment in hundreds of metric tons for many years and have been used in diverse applications such as industry and agriculture. Although they were banned in most countries, their residues are still widespread in the environment. Because of their high lipophilicity and structural stability, they still can be found accumulated in biological systems. They show a carcinogenic and an endocrine disruption potential. Recently, based on epidemiological studies, there has been concern about their speculated association with metabolic disturbances like diabetes mellitus type 2, rheumatoid arthritis, disturbances of cognitive function, etc. Contaminated food, especially fatty fish, meat and milk products, is still a main source of the exposure of general population (1).

Among chlorinated pesticides, $\mathrm{p}, \mathrm{p}^{\prime}$-DDT has been used most extensively. Its metabolite $\mathrm{p}, \mathrm{p}^{\prime}$-DDE together with hexachlorocyclobenzene ( $\mathrm{HCB})$ are, at the present day, the most frequently prevalent residues in the adipose tissue of humans (2).

PCBs form a subgroup of halogenated aromatic hydrocarbons. There are theoretically 209 single congeners. They have been used, to a great extent, in diverse technical applications from the 1930s to the 1970s (3). Despite production bans in many industrial countries in the 1970s and 1980s, about 113 different PCB congeners were still detectable in the environment in 1998 (4). Their concentration in human tissue is generally monitored by using examinations of human breast milk and data from Europe show their decreased concentration. 'Non-dioxin-like' PCB 153, 138, and 180 are the main congeners which show the highest concentration and are most frequently found in breast milk (5). In the former Czechoslovakia, PCB was marketed as technical mixtures under the trade name "Delor" produced in the amount of about 21,500 tons in Eastern Slovakia from 1959 to 1984, when the production was finally abolished (6). About 11,600 tons were used inside the former Czechoslovakia (7). Therefore, the industrial areas of the Czech Republic have one of the highest PCB burdens of all European countries (8).

After human exposure, POPs are accumulated in the body, especially in the adipose tissue. They have relatively long halflives before disappearing from the tissue or from the body. The variability of the stored amount depends on dietary exposure (food habits, and the quality and quantity of POPs in available food) and on individual disposition to store these substances (genetic traits and size of adipose tissue and its dynamic changes) (9). Their 
distribution in the body is affected by changes in body weight. Weight loss resulted in an acute increase of their concentration in reduced adipose tissue, brain, and serum/plasma without changing the total amount, as it was documented in case of hexachlorocyclohexane (HCH) (10). However, dramatic weight loss, which occurred as a consequence of bariatric surgery treatment, showed not only an increased level of serum and adipose tissue POPs concentrations together with a reduced amount of white adipose tissue, but a decreased total body burden for POPs after 12 months post-surgery as well (11). The objective of our study was to analyze in five year follow up study the development of plasma POPs levels in obese women in relationship to their weight loss success, caused by restrictive diet regimen.

\section{MATERIALS AND METHODS}

Twenty obese adult women, aged $25-73$ years (BMI $>30 \mathrm{~kg}$ / $\mathrm{m}^{2}$ ) were randomly selected from the patients of the Centre for Obesity Treatment (Faculty Hospital in Pilsen, Czech Republic) during their first visit in 2006. Informed consent was obtained from all patients involved in the study. Anthropometry: body weight $(\mathrm{BW})$ and height were measured, and a plasma analysis of 7 POPs (p,p'-DDE, p,p'-DDT, HCB, HCH ß, PCB 153, 138, $180)$ was performed in all the subjects. Obese patients were studied just before (Time 1, T1) and after the 3 month (Time 2, T2) of low calorie diet (LCD) intervention (5 MJ daily, protein $20 \%$ of total energy, fat $25-30 \%$ of total energy). Their diaries were checked on a monthly basis using nutritional software NutriDan 1.2 (DADI Ltd., Pilsen, 2002, Czech Republic). After that period they were instructed to continue their diet and were checked again 6 months (Time 3, T3) and 60 months (Time 4, T4) after the beginning of the study.

Venous blood was collected in time T1, T2, T3, and T4 from fasted (12 hours) subjects between 7.00 a.m. and 10.00 a.m. Plasma samples were divided into $50 \mu \mathrm{l}$ aliquots and stored at $-80^{\circ} \mathrm{C}$ for subsequent analysis of PCB $153,138,180, \mathrm{p}, \mathrm{p}^{\prime}-\mathrm{DDE}$, p,p'-DDT, HCH $\beta$ and HCB. Plasma levels of these pollutants were determined by a high resolution gas chromatography with electron capture detection (HRGC/ $\mu \mathrm{ECD}$; Agilent Technologies 6890 Series, Palo Alto, CA, USA), Capillary Column DB-5 (0.25 $\mathrm{mm} \times 60 \mathrm{~m} \times 0.25 \mu \mathrm{m}$ ); J\&W Scientific, USA (12). The values (in $\mathrm{ng} / \mathrm{kg}$ fat) of the detection limit (LOD) were the following: $\mathrm{PCB}$ $153(<20)$, PCB $138(<60)$, PCB $180(<40)$; p, p'-DDE $(<10)$; p,p'-DDT $(<50), \mathrm{HCB}(<20), \mathrm{HCH} \beta(<40)$.

\section{Statistics}

POPs concentration values below the detection limit were treated as one-half the value of the detection limit (LOD). The descriptive statistics including the median and range (minimum -maximum) were calculated only for the congeners detected in at least $50 \%$ of samples.

Due to the not normal distribution of most of the examined variables, the non-parametric Wilcoxon Rank-Sum Test was performed to compare the POP concentration increase during a 60 month period between WG and WL/M groups. All statistical computations were performed with the MATLAB Statistics Toolbox.

We certify that all applicable institutional and governmental regulations concerning the ethical use of human volunteers were followed during this research. The approval of the protocol examination was authorized by the Medical School and Faculty Hospital Ethics Committee in Pilsen.

\section{RESULTS}

Basic characteristics of plasma concentration development of each measured POP in whole sample during the five-year follow up are summarized in Table 1, BW development in Table 2. During this time, i.e. from 2006 to 2011, only plasma levels of $\mathrm{HCH} \beta$ and DDT decreased. The median and range of all others

Table 1. Development of plasma concentration of PCB congeners and chlorinated pesticides/metabolites; $(n=20)$

\begin{tabular}{|c|c|c|c|c|}
\hline & $\mathrm{T} 1$ & $\mathrm{~T} 2$ & $\mathrm{~T} 3$ & $\mathrm{~T} 4$ \\
\hline \multirow{2}{*}{$\mathrm{HCH}$-beta } & 20 & 570 & 350 & 230 \\
\hline & $20-2,390$ & $140-4,370$ & $170-5,350$ & $100-440$ \\
\hline \multirow{2}{*}{$\mathrm{HCB}$} & 175 & 450 & 270 & 935 \\
\hline & $10-880$ & $40-2,440$ & $120-1,570$ & $100-4,470$ \\
\hline \multirow{2}{*}{$p, p^{\prime}-D D E$} & 160 & 385 & 27 & 1,435 \\
\hline & $5-700$ & $100-1,500$ & $150-1,410$ & $210-8,180$ \\
\hline \multirow{2}{*}{$p, p^{\prime}-D D T$} & 25 & 46 & 41 & 100 \\
\hline & $25-1,740$ & $37-610$ & $41-410$ & $100-290$ \\
\hline \multirow{2}{*}{ PCB 138} & 30 & 150 & 160 & 705 \\
\hline & $30-140$ & $80-340$ & $110-330$ & $350-1,110$ \\
\hline \multirow{2}{*}{ CB 153} & 140 & 190 & 205 & 780 \\
\hline & $10-500$ & $60-620$ & $130-420$ & $280-1,260$ \\
\hline \multirow{2}{*}{ CB 180} & 20 & 110 & 90 & 765 \\
\hline & $20-140$ & $60-180$ & $70-230$ & $150-1,520$ \\
\hline
\end{tabular}

Median; minimum-maximum, expressed in ng/kg, T1 - initial measurement, prior diet restriction, T2 - measurement after 3 months of LCD intervention, T3 measurement after 6 months from the beginning of the study, T4 - measurement after 60 months from the beginning of the study 
Table 2. Development of body weight

\begin{tabular}{|c|c|c|c|}
\hline T1 & T2 & T3 & T4 \\
\hline 108.2 & 101.6 & 99 & 108.8 \\
\hline $82.8-130.5$ & $74.7-118.5$ & $73-115$ & $77.9-120.4$ \\
\hline
\end{tabular}

Median, minimum-maximum, expressed in kg, T1 - initial measurement, prior diet restriction, T2 - measurement after 3 months of LCD intervention, T3 measurement after 6 months from the beginning of the study, T4 - measurement after 60 months from the beginning of the study

examined POPs increased. The highest plasma levels detected were DDE and HCB (Fig. 1). The medians of HCB and DDE are also depicted as the central line in the box plots in Figure 3.

To show the dependency of the increase of pollutant concentration between $\mathrm{T} 4 \mathrm{a} \mathrm{T} 1$ on relative weight growth, the linear regression of the increase of pollutant concentration $\left(\mathrm{POP}_{\mathrm{T} 4}-\right.$ $\left.\mathrm{POP}_{\mathrm{T} 1}\right) \cdot 10^{6}$ on relative weight growth $\left(\mathrm{BW}_{\mathrm{T} 4}-\mathrm{BW}_{\mathrm{T} 1}\right) / \mathrm{BW}_{\mathrm{T} 1} \cdot 100$ is represented in Fig. 2.

Depending on body weight difference between time 4 and time 1, the sample was divided into two cohorts: women whose $\mathrm{BW}$ decreased or remained relatively stable $\left(\mathrm{BW}_{\mathrm{T} 4}-\mathrm{BW}_{\mathrm{T} 1}<1.5\right.$ $\mathrm{kg}$ ) (weight losers/maintainers - WL/M, N=11); and the others

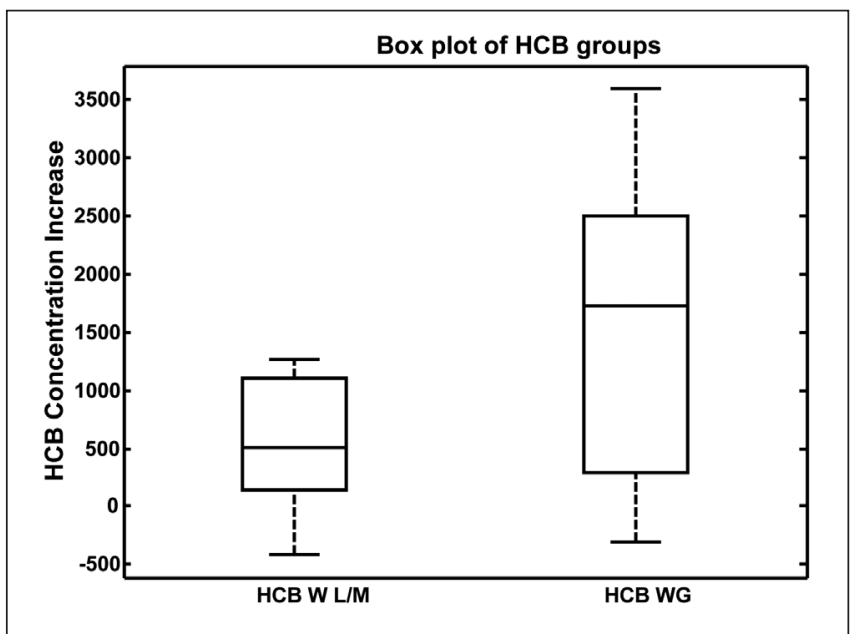

Fig. 3. The box plot of HCB, in ng/kg lipids; median is depicted as the central line. $p<0.05$, Wilcoxon's test
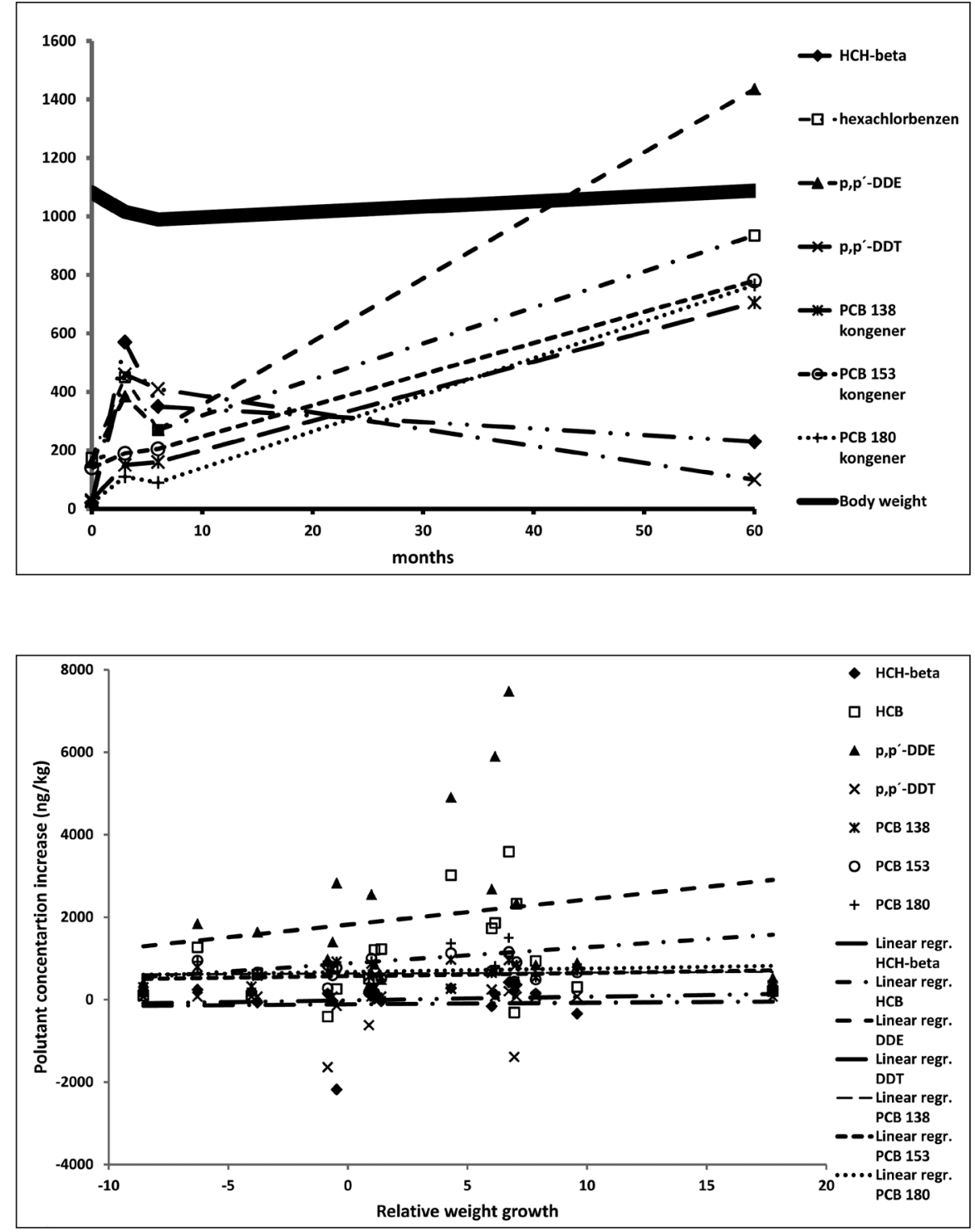

Fig. 1. The development of plasma POPs levels (medians, in ng/kg lipids) and body weight (in $\mathrm{kg} \cdot 10$ ) during fiveyear follow-up.
Fig. 2. The linear regression of the increase of pollutant concentration $\left(P O P_{T 4}-P O P_{T 1}\right) \cdot 10^{6}$ on relative weight growth $\left(B W_{T 4}-B W_{T 1}\right) / B W_{T 1} \cdot 100$. 
(weight gainers $\mathrm{WG}, \mathrm{N}=9$ ). WL/M had lower plasma level of $\mathrm{HCB}$ in comparison to WG in T4 $(\mathrm{p}<0.05)$, although they did not differ in T1 (Table 2, Fig. 3). A similar tendency, however without statistical significance $(p<0.1)$, was also observed in DDE. Some tendency was also observed for other POPs but without statistical significance $(p>0.1)$. These results suggest that long term weight loss or weight maintenance tend to be positively associated with a lower plasma level of HCB contrary to the HCB plasma level in weight gainers.

\section{DISCUSSION}

During a five years follow up study from 2006 to 2011, there were increased medians levels of 5 from 7 examined POPs. Many studies confirmed age as a predictor of POPs levels (13, 14). In case of body weight and body composition maintenance, the increase of POPs plasma levels is the result of an imbalance between increased body burden from everyday exposure to food and their slower degradation and elimination from the body. Taking into account that biological half-time of many POPs is around ten years; there is a high probability of an accumulation of these POPs in the body, especially in lipophilic tissue. Intergeneration differences along with the gradual reduction of body burden, reflect a gradual decrease of background exposure from the environment as a result of the Stockholm Convention (15). It depends on the amount of particular POP which has been released into the environment and also on its chemical properties for degradation. Based on our data, only DDT and $\mathrm{HCH} \beta$ have been reduced during the five-year follow up study. The situation in POPs body distribution is more complicated with the changing of the fat/fat-free mass compartments, as it occurs with the development of overweight and obesity. There are studies which suggest an inverse association between PCB levels and BMI gain over the last ten years (16). On the other hand, weight loss, and especially drastic weight loss, is associated with increased plasma/serum levels in the liver, brain, and in a reduced size of white adipose tissue. The knowledge of these dynamics along with total POPs body burden development is very important for an obesity treatment strategy.

\section{CONCLUSION}

The results of our study, where the subjects tried to keep lifestyle modification based on energy and total fat restriction in their diet, show that after 3 months of completely controlled regime, the weight loss was associated with an increase in POP plasma levels. However, after the five-year follow up, there were no differences in POPs plasma levels between the group of long-term successful WL/M and the group of WG, except for HCB where the WG had a significantly higher level.

\section{Conflict of Interests}

None declared

\section{Sponsorship}

Sponsored by the Ministry of Health of the Czech Republic, grant: No. NT14330-3/2013, Polychlorinated persistent organic pollutants in the etiopathogenesis of obesity and insulin resistance

\section{REFERENCES}

1. Smeds A, Saukko P. Identification and quantification of polychlorinated biphenyls and some endocrine disrupting pesticides in human adipose tissue from Finland. Chemosphere. 2001 Sep;44(6):1463-71.

2. Hardell E, Carlberg M, Nordström M, van Bavel B. Time trends of persistent organic pollutants in Sweden during 1993-2007 and relation to age, gender, body mass index, breast-feeding and parity. Sci Total Environ. 2010 Sep 15;408(20):4412-9.

3. Safe SH. Polychlorinated biphenyls (PCBs): environmental impact, biochemical and toxic responses, and implications for risk assessment. Crit Rev Toxicol. 1994;24(2):87-149.

4. Crisp TM, Clegg ED, Cooper RL, Wood WP, Anderson DG, Baetcke $\mathrm{KP}$, et al. Environmental endocrine disruption: an effects assessment and analysis. Environ Health Perspect. 1998 Feb; 106(Suppl 1): 11-56.

5. Bencko V, Skulová Z, Krecmerová M, Liem AK. Selected polyhalogenated hydrocarbons in breast milk. Toxicol Lett. 1998 Aug;96-97:341-5.

6. Pavuk M, Cerhan JR, Lynch CF, Schecter A, Petrik J, Chovancova J, Kocan A. Environmental exposure to PCBs and cancer incidence in eastern Slovakia. Chemosphere. 2004 Mar;54(10):1509-20.

7. Černá M, Malý M, Grabic R, Batáriová A., Šmíd J, Beneš B. Serum concentrations of indicator PCB congeners in the Czech adult population. Chemosphere. 2008 Jul;72(8):1124-31.

8. Černá M, Bencko V, Brabec M, Šmíd J, Krsková A, Jech L. Exposure assessment of breast-fed infants in the Czech Republic to indicator PCBs and selected chlorinated pesticides: Area-related differences. Chemosphere. 2010 Jan;78(2):160-8.

9. Müllerová D, Kopecký J. White adipose tissue: storage and effector site for environmental pollutants. Physiol Res. 2007;56(4):375-81.

10. Jandacek RJ, Anderson N, Liu M, Zheng S, Yang Q, Tso P. Effects of yo-yo diet, caloric restriction, and olestra on tissue distribution of hexachlorobenzene. Am J Physiol Gastrointest Liver Physiol. 2005 Feb;288(2):G292-9.

11. Kim MJ, Marchand P, Henegar C, Antignac JP, Alili R, Poitou C, et al. Fate and complex pathogenic effects of dioxins and polychlorinated biphenyls in obese subjects before and after drastic weight loss. Environ Health Perspect. 2011 Mar;119(3):377-83.

12. Karásek L, Hajslová J, Rosmus J, Hühnerfuss H. Methylsulfonyl PCB and DDE metabolites and their enantioselective gas chromatographic separation in human adipose tissues, seal blubber and pelican muscle. Chemosphere. 2007 Apr;67(9):S22-7.

13. Covaci A, de Boer J, Ryan JJ, Voorspoels S, Schepens P. Distribution of organobrominated and organochlorinated contaminants in Belgian human adipose tissue. Environ Res. 2002 Mar;88(3):210-8.

14. Kiviranta H, Tuomisto JT, Tuomisto J, Tukiainen E, Vartiainen T. Polychlorinated dibenzo-p-dioxins, dibenzofurans, and biphenyls in the general population in Finland. Chemosphere. 2005 Aug;60(7):854-69.

15. Hardell E, Carlberg M, Nordström M, van Bavel B. Time trends of persistent organic pollutants in Sweden during 1993-2007 and relation to age, gender, body mass index, breast-feeding and parity. Sci Total Environ. 2010 Sep 15;408(20):4412-9.

16. Bachelet D, Truong T, Verner MA, Arveux P, Kerbrat P, Charlier C, et al. Determinants of serum concentrations of 1,1-dichloro-2,2-bis(pchlorophenyl)ethylene and polychlorinated biphenyls among French women in the CECILE study. Environ Res. 2011 Aug;111(6):861-70.

Received September 10, 2014 Accepted in revised form December 22, 2014 